\title{
Research on Congenital Heart Defects: A Bibliometric Assessment of India's Publications during 2000-19
}

\author{
BM Gupta ${ }^{1, *}$, KK Mueen Ahmed $^{2}$
}

BM Gupta ${ }^{1, *}$, KK Mueen Ahmed $^{2}$

'Formerly with CSIR-, New Delhi, INDIA. 2Phcog.Net, Bengaluru, Karnataka, INDIA.

\section{Correspondence \\ Dr. BM Gupta, \\ Formerly with CSIR-, New Delhi-11012, INDIA. \\ Mobile no: +91-9888378275 \\ Email: bmgupta1@gmail.com \\ History \\ - Submission Date: 21-09-2020 \\ - Revised Date: 15-10-2020 \\ - Accepted Date: 02-11-2020}

DOI : 10.5530/ijmedph.2020.4.46

Article Available online

http://www.ijmedph.org/v10/i4

\section{Copyright}

(C) 2020 Phcog.Net. This is an openaccess article distributed under the terms of the Creative Commons Attribution 4.0 International license.

\begin{abstract}
The paper presents a quantitative and qualitative dimensions of congenital heart defect (CHD) research output in India, based on publications data (1335) indexed in Scopus database during 2000-19. CHD research registered 10.0\% growth, averaged 7.07 citations per paper, contributed $3.04 \%$ share to the global output and constitute $13.48 \%$ share of India's research as international collaborative. CHD research is skewed as top 10 countries account for $83.23 \%$ of global output. India ranks as the $10^{\text {th }}$ most productive country in the world. The distribution of $\mathrm{CHD}$ research by type of research reveal that Tetralogy of Fallout accounted for the highest share (34.31\% share), followed by Aortic Stenosis (30.41\%), Atrial Septal Defects (28.16\%), Ventricular Septal Defects (26.22\%), etc. AlIMS - New Delhi, Amrita Institute of Medical Sciences, Coimbatore and PGIMER - Chandigarh lead the country as the most productive organizations (with 222, 73 and 64 papers). Besides, Amrita Institute of Medical Sciences, Coimbatore (33.88 and 4.79), SCTIMST - Trivandrum (30.73 and 4.35) and Institute of Medical Sciences, BHU, Varanasi (17.20 and 2.43) lead the country as the most impactful organizations in terms of citation per paper and relative citation index. B. Airan, A. Saxena and S. Talwar have been the most productive authors (with 63, 63 and 59 papers) and P. Khairy (16.31 and 2.31), B. Vaidyanathan (14.3 and 2.03) and R.K. Kumar (10.53 and 1.49) have been the most impactful authors. Indian Heart Journal, Annals of Pediatric Cardiology (84 papers) and Annals of Cardiac Anaesian (53 papers) topped the list of most productive journals (with 110, 84 and 53 papers). International Journal of Cardiology (18.62), Catheterization and Cardiovascular Interventions (16.64) and Journal of Cardiothoracic and Vascular Anesthesia (11.65) leads in ranking in terms of citation per paper.

Key words: Congenital Heart Defects, Indian publications, Scientometrics, Bibliometrics.
\end{abstract}

\section{INTRODUCTION}

Congenital heart disease (or defecs) (CHD) is defined as a gross structural abnormality of the heart or intrathoracic great vessels that causes significant functional impairment. ${ }^{1}$ It simply means that it is a type of birth defect which can involve the walls of the heart, the valves of the heart and the arteries and veins (the large blood vessels) that lead to and from the heart. ${ }^{2}$ The etiology of congenital heart diseases is still elusive. The developmental process of the heart is a tightly regulated process that requires intricate interplay between cardiac transcription factors, several cardiac-specific genes and signaling pathways, which are responsible for early cardiac morphogenesis. Both genetic and environmental factors play essential roles during cardiac development. Gene mutations and some teratogens can interfere with normal development (embryogenesis) of the heart leading to congenital heart defects. ${ }^{3}$ Studies have also implicated non-hereditary risk factors such as rubella infection, teratogens, maternal age, diabetes mellitus, abnormal hemodynamics use of certain medications or drugs such as alcohol or tobacco, parents being closely related or poor nutritional status or obesity in the mother, besides having a parent with a congenital heart defect is also a risk factor in causing CHDs. ${ }^{3,4}$

The most common CHD including left-to-right shunts (atrial septal defect, ventricular septal defect, atrioventricular septal defect, patent ductus arteriosus and others), obstructive lesions (pulmonary stenosis, aortic stenosis and coarctation of aorta) and cyanotic CHD (tetralogy of Fallot, transposition of great arteries, univentricular hearts, total anomalous pulmonary venous connection, Ebstein's anomaly and others). ${ }^{5}$ Congenital heart defects are classified clinically, as cyanotic and acyanotic. Bluish discoloration of mucous membrane clinically characterizes cyanotic heart defects due to an increased level of deoxygenated hemoglobin. Therefore, cyanotic congenital heart defects are regarded as the most severe forms of CHDs. ${ }^{3}$ Clinical presentations and severity of CHDs depend on their types or sub-types. However, most children with CHDs present with failure to thrive, cough, repeated chest infections, difficulty in breathing, exercise intolerance and bluish discoloration of mucous membranes (cyanosis). Congenital heart defects are
Cite this article : Gupta BM, Ahmed KKM. Research on Congenital Heart Defects: A Bibliometric Assessment of India's Publications during 2000-19. Int J Med Public Health. 2020;10(4):217-25. 
associated with serious complications such as cognitive impairment and often affect families and individuals both emotionally and financially.,

Diagnostic and treatment capabilities for congenital heart disease have dramatically improved over the past. Many studies show substantial improvement in survival in developed regions of the world, but the same success rates are not yet seen in developing regions. Despite some improvements in the past two decades, neonates in low-income and middle-income countries (LMICs) with severe forms of congenital heart disease and without access to surgical treatment are more likely to die before their fifth birthday than are those in high income countries. Additional premature mortality might occur secondary to cardiac and pulmonary complications.

The congenital heart defects (CHDs) are the most frequent congenital anomalies and affect a large number of newborns accounting for a high proportion of infant mortality worldwide. There are regional differences in the prevalence and distribution pattern of CHDs. Globally, twentyeight percentage of all major congenital anomalies consist of heart defects and along with neural tube defects they account for two-thirds of all congenital malformations. ${ }^{1}$ The birth prevalence of CHD is reported to be $8-12 / 1000$ live births. Considering a rate of $9 / 1000$, about 1.35 million babies are born with CHD each year globally. ${ }^{6}$

Considering a birth prevalence as $9 / 1000$, the estimated number of children born with CHD every year in India approximates 240,000, posing a tremendous challenge for the families, society and health care system. About one-fifth of these suffer from critical heart disease requiring early intervention. The currently available care for these children is grossly inadequate. There are over 60 centers that cater to children with congenital heart disease; majority are in southern states of India. Most of babies born with congenital heart disease in most populous states of India, such as Uttar Pradesh and Bihar, do not receive the care they deserve. Improving care of children with congenital heart disease is an uphill task, but needs to be addressed. ${ }^{6}$

A number of guidelines are available for the management of congenital heart diseases (CHD) from infancy to adult life. However, these guidelines are for patients living in high-income countries. Separate guidelines, applicable to Indian children, are required when recommending an intervention for $\mathrm{CHD}$, as often these patients present late in the course of the disease and may have coexisting morbidities and malnutrition. Guidelines emerged following expert deliberations at the National Consensus Meeting on Management of Congenital Heart Diseases in India, held on August 10 and 11, 2018, at the All India Institute of Medical Sciences. These evidence-based guidelines aims at (i) indications and optimal timing of intervention in common CHD; (ii) follow-up protocols for patients who have undergone cardiac surgery/catheter interventions for CHD; and (iii) indications for use of pacemakers in children. Evidence-based recommendations are provided for indications and timing of intervention in common CHD. In addition, protocols for follow-up of postsurgical patients are also described, disease wise. Guidelines are also given on indications for implantation of permanent pacemakers in children. ${ }^{5}$

\section{Literature Review}

Bibliometric/scientometric studies related to analysis of "Contenital Heart Disease/defects" covering publications and patents, are only few. Amongst the existing studies, Farhat,, Abdul-Sater, Obeid, Arabi Diab, Masri, Al Hales, Nemer and Bitar ${ }^{7}$ made a bibliometric assessment and compared the contribution of the Arab countries (530 articles) with that of the United States (12936 articles) and Europe (12260 articles), in contenital heart disease using MEDLINE, PubMed and Scopus databases. Basic research relating to genetics and animal models of CHD is emerging sparsely in the Arab world, with few articles published in high-impact-factor journals. The Arab world research output in the field of CHD per capita is substantially low, estimated to be 29 times less than in developed countries. Despite the minimal increase in published research articles, most of the research relating to CHD continues to be far from innovative. Regional collaborations with international linkage are starting to evolve. The research facilities in the Arab countries need to increase substantially in research and infrastructure funding to keep up with the pace of research in developing countries. Hsieh, Chiu, Lee et al. ${ }^{8}$ made a bibliometric analysis of Patent Ductus Arteriosus (PDA) treatment research, including intravenous injection of indomethacin and surgery using Science Citation Index (SCI) during 1991-2002. The publication pattern concerning authorship, collaboration, original countries, citation frequency, document type, language of publication, distribution of journals, page count and the most frequently cited papers were performed. The results indicated that either treatment was not the recent emphasis of PDA research. van Doren, Brida, Gatzoulis et al. ${ }^{9}$ examine quantum and factors associated with female representation in 35118 global CHD publications during 2006-15. It observed that $25.0 \%$ of all authors were female and women constituted for $30.2 \%$ and $20.8 \%$ of all first and senior authorship positions with great geographic heterogeneity. Significant predictors of female first authorship on logistic regression analysis were country gross domestic product, human development index, gender inequality index and a female senior author $(p<0.0001$ for all). Conclusions While modest improvement in female authorship over time was noted, women remain underrepresented in contemporary academic CHD

In view of non-availablity of any bibliometric study on congenital heart defects publications at national level and India being contributing to largest share of newborns and infants in global mortality, we decided to carry out the present study. The study aims to examine the qualitative and qualitative aspects of India's overall research output in the area of congenital heart defects as indexed in Scopus database during 2000-19. In particular, the study focuses and analyses: global research output in terms of publications growth and global share of top 10 most productive countries, congenital heart defects (CHD) research in India in terms of publications growth, its distribution by document and source types, broad subject areas and type of congenital heart defects, CHD research in India in terms of citation impact and describe bibliographic features of highly-cited papers and top 20 most productive organizations and authors and top 20 journals for research communications.

\section{MATERIALS AND METHODS}

In order to undertake a study of India's contribution in the congenital heart defects research, data on publications was sourced from the Scopus database (http://www.scopus.com) covering 20-year period 2000-19. A set of keywords such as "congenital heart anomaly" or "congenital heart defect" or "congenital heart disease" or "congenital heart malformation" or "hypoplastic heart syndrome" or "Obstructive heart defects" or "Septal heart defects" or "Cyanotic heart defects" were used in "Keyword tag" as well as in "Article Title tag" (joined by Bolean operator "OR") simultaneously and restricted the output to period "2000-19" to get global publication data (consisting of 43888 records). The above described search strategy was refined by country of publication (including India) to get publication output data on top 10 countries. India's publication output comprised of 1335 records. The search strategy for obtaining India's output was further refined to get statistics on India's output by subject, collaborating country, organization, author and journal. Citations to publications were counted from date of their publication till 9 May 2020. Separate search strategies were formulated to get data on various types of congenital heart defects. A complete counting method, 
wherein every contributing author or organization covered in multiple authorship papers was fully counted and used.

(KEY("congenital heart anomaly" or "congenital heart defect" or "congenital heart disease" or "congenital heart malformation" or "hypoplastic heart syndrome" or "Obstructive heart defects" or "Septal heart defects" or "Cyanotic heart defects") OR TITLE ("congenital heart anomaly" or "congenital heart defect" or "congenital heart disease" or "congenital heart malformation" or "hypoplastic heart syndrome" or "Obstructive heart defects" or "Septal heart defects" or "Cyanotic heart defects")) AND PUBYEAR > 1999 AND PUBYEAR < 2020 AND (LIMIT-TO ( AFFILCOUNTRY,'India"))

\section{Analysis}

\section{Publication Growth}

The global and Indian research output in field of "Congenital Heart Defects" (CHD) in 20 years was 43888 and 1335 publications during 2000-19, an average of 2194.4 and 66.75 publications per year. India registered $10.0 \%$ growth compared to $6.64 \%$ by the world. India's absolute growth between 2000-09 and 2010-19 was 147.66\% compared to $79.40 \%$ by the world. India contributed $3.04 \%$ share to global output in 20 years; its 10 -year global publications share surged from $2.44 \%$ (2000-09) to $3.37 \%$ (2010-19). In the field of CHD research, India's citation impact on a 20 -year window averaged to 7.07 citations per paper (CPP) and its 10-year citation impact dropped from 9.17 CPP to 6.22
CPP during 2000-09 to 2010-19. Only 55 out 1335 India's publications are observed to be funded by national and international funding agencies. These 55 funded papers received 3680 citations, averaging 66.91 citations per paper (Table 1). Of the total publications, $75.13 \%$ appeared as articles, 9.44\% as reviews, $6.74 \%$ as letters, $3.52 \%$ as notes, $2.47 \%$ as conference papers, $0.67 \%$ as short surveys and $1.87 \%$ as editorials and $0.67 \%$ as book chapters.

\section{Top Ten Most Productive Countries}

In all, 162 countries participated in global Congenital Hear Defects (CHD) research. The distribution of $\mathrm{CHD}$ research across participating countries was uneven. For instance, 68 countries published 1-10 papers, 40 published $11-50$ papers, 8 published $51-100$ papers, 27 published 101500 papers, 6 published $601-1000,12$ published $1001-3698$ papers and 1 published 15705 .

Bulk of the global research output (83.23\%) in the field was contributed by top 10 most productive countries alone, which increased from $78.10 \%$ to $86.08 \%$ during $2000-09$ to $2010-19$. USA is in the leadership position in the world ranking, accounting for $35.78 \%$ global publications share and other 9 countries has been in single digit ranging between 3.04\% and $8.43 \%$. India ranked at $10^{\text {th }}$ position, with global share of $3.04 \%$. The global publication share increased in China, USA, India, Canada and Netherlands (from $0.48 \%$ to $5.52 \%$ ), as against decrease in Italy, France,

Table 1: Annual and Cumulative Publications on “Congenital Heat Defects (CHD) in India during 2000-19.

\begin{tabular}{|c|c|c|c|c|c|c|c|c|}
\hline \multirow[b]{2}{*}{ Publication Year } & \multirow[b]{2}{*}{$\begin{array}{c}\text { Global } \\
\text { Publications } \\
\text { (TP) }\end{array}$} & \multicolumn{7}{|c|}{ Indian Publications } \\
\hline & & TP & TC & CPP & \%TP & ICP & $\%$ ICP & FP \\
\hline 2000 & 1006 & 31 & 264 & 8.52 & 3.08 & 2 & 6.45 & \\
\hline 2001 & 1131 & 33 & 277 & 8.39 & 2.92 & 1 & 3.03 & \\
\hline 2002 & 1312 & 32 & 464 & 14.50 & 2.44 & 3 & 9.38 & \\
\hline 2003 & 1438 & 22 & 319 & 14.50 & 1.53 & 2 & 9.09 & \\
\hline 2004 & 1518 & 33 & 209 & 6.33 & 2.17 & 7 & 21.21 & \\
\hline 2005 & 1715 & 52 & 605 & 11.63 & 3.03 & 2 & 3.85 & 3 \\
\hline 2006 & 1902 & 29 & 264 & 9.10 & 1.52 & 4 & 13.79 & 1 \\
\hline 2007 & 1759 & 42 & 283 & 6.74 & 2.39 & 2 & 4.76 & \\
\hline 2008 & 1907 & 57 & 470 & 8.25 & 2.99 & 8 & 14.04 & 1 \\
\hline 2009 & 2020 & 53 & 365 & 6.89 & 2.62 & 8 & 15.09 & \\
\hline 2010 & 2231 & 72 & 517 & 7.18 & 3.23 & 6 & 8.33 & 1 \\
\hline 2011 & 2346 & 67 & 446 & 6.66 & 2.86 & 4 & 5.97 & 11 \\
\hline 2012 & 2361 & 86 & 368 & 4.28 & 3.64 & 12 & 13.95 & 1 \\
\hline 2013 & 2633 & 79 & 2156 & 27.29 & 3.00 & 13 & 16.46 & 1 \\
\hline 2014 & 2908 & 100 & 497 & 4.97 & 3.44 & 13 & 13.00 & 2 \\
\hline 2015 & 2838 & 114 & 626 & 5.49 & 4.02 & 14 & 12.28 & 3 \\
\hline 2016 & 2979 & 108 & 394 & 3.65 & 3.63 & 14 & 12.96 & 4 \\
\hline 2017 & 3198 & 113 & 530 & 4.69 & 3.53 & 18 & 15.93 & 6 \\
\hline 2018 & 3371 & 108 & 286 & 2.65 & 3.20 & 20 & 18.52 & 17 \\
\hline 2019 & 3315 & 104 & 96 & 0.92 & 3.14 & 27 & 25.96 & 9 \\
\hline 2000-09 & 15708 & 384 & 3520 & 9.17 & 2.44 & 39 & 10.16 & 5 \\
\hline 2010-19 & 28180 & 951 & 5916 & 6.22 & 3.37 & 141 & 14.83 & 55 \\
\hline 2000-19 & 43888 & 1335 & 9436 & 7.07 & 3.04 & 180 & 13.48 & \\
\hline
\end{tabular}

TP=Total Papers; TC=Total Citations; $\mathrm{CPP}=$ Citations Per Paper; ICP=International Collaborative Papers 
Japan, U.K. and Germany (from $0.13 \%$ to $1.95 \%$ ) during $2000-09$ to 2010-19 (Table 2).

\section{India's International Collaboration}

The share of international collaborative papers (180) in India's total output (1335) was $13.48 \%$ during $2000-19$, which increased from $10.16 \%$ during 2000-09 to $14.83 \%$ during $2010-19$. The 180 international collaborative papers spread over 100 countries have received 6587 citation, averaging 136.59 citations per paper. India's collaboration with the USA was the largest (51.11\% of India's ICP output), followed by U.K. and Canada (24.44\% and $22.78 \%$ ) and for other 7 countries it varied from $10.56 \%$ to $18.33 \%$ during 2000-19 (Table 3).

\section{Subject-Wise Distribution of India's Research Output}

Medicine research in India intersected with 3 disciplines (as identified in Scopus database classification). Of these, medicine has been the most favored subject areas in CHD research pursuits (with $92.88 \%$ publications share), followed by biochemistry, genetics and molecular biology $(7.79 \%)$ and pharmacology, toxicology and pharmaceutics (2.47\%). Research activity index in all subjects of increased in biochemistry, genetics and molecular biology (from 27.47 to 129.58) and pharmacology, toxicology and pharmaceutics (from 42.14 to 123.36), as against decrease in medicine (from 105.14 to 97.93) between 2000-09 and 2010-19. Medicine recorded the highest citation impact per paper of 9.09 and pharmacology, toxicology and pharmaceutics the least (7.55) during 2000-19 (Table 4).

\section{Distribution of Publications by Type Heart Defects}

In all, CHD are classified under two types: Hydroplasia and Obstructive defects. The obstructive defects are further classified as ventrivular outflow tract obstruction, septual defects and cyanotic defects. The above two type of defects are further classified under 15 subcategories as shown in Table 5. Under various subcategories of CHD, the largest contribution has been made by Tetralogy of Fallout (458 papers, $34.31 \%$ ), followed by Aortic Stenosis (406 papers, 30.41\%), Atrial Septal Defects (376 papers, 27.55\%), Ventricular Septal Defects (350 papers, 26.22\%), Transposition of the Great Vessels (204 papers, 15.28\%), Tricuspid Atresia (86 papers. $6.44 \%)$, etc.

\section{India's Top 25 Most Productive Organizations}

In all, 431 organizations participated in Indian research on CHD during 2000-19, of which 303 organizations published 1-5 papers each, 76 organizations published 6-10 papers each, 45 organizations $11-20$ papers each, 4 organizations 21-50 papers each, 2 organizatons 51-100

Table 2: Congental Heart Defects: Top 10 Most Productive Countries during 2000-19.

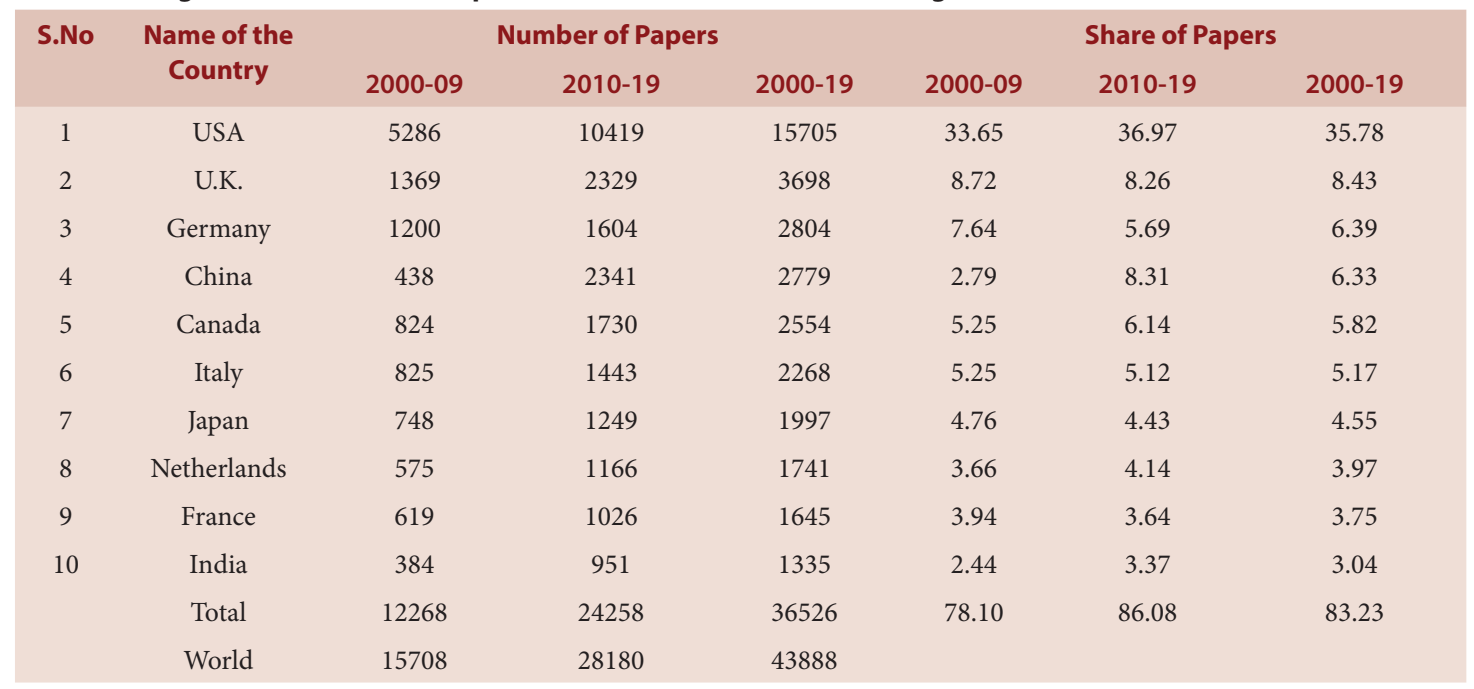

Table 3: India' International Collaboration with Top 10 Countries in CHD Research during 2000-19.

\begin{tabular}{|c|c|c|c|c|c|c|c|}
\hline \multirow[t]{2}{*}{ S.No. } & \multirow[t]{2}{*}{ Collaborative Country } & \multicolumn{3}{|c|}{ International Collaborative Papers (ICP) } & \multicolumn{3}{|c|}{ Share of ICP } \\
\hline & & 2000-09 & 2010-19 & 2000-19 & 2000-09 & 2010-19 & 2000-19 \\
\hline 1 & USA & 12 & 80 & 92 & 30.77 & 56.74 & 51.11 \\
\hline 2 & U.K. & 5 & 39 & 44 & 12.82 & 27.66 & 24.44 \\
\hline 3 & Canada & 4 & 37 & 41 & 10.26 & 26.24 & 22.78 \\
\hline 4 & Australia & 2 & 31 & 33 & 5.13 & 21.99 & 18.33 \\
\hline 5 & Italy & 3 & 26 & 29 & 7.69 & 18.44 & 16.11 \\
\hline 6 & France & 2 & 26 & 28 & 5.13 & 18.44 & 15.56 \\
\hline 7 & Netherlands & 0 & 25 & 25 & 0.00 & 17.73 & 13.89 \\
\hline 8 & Switzerland & 0 & 25 & 25 & 0.00 & 17.73 & 13.89 \\
\hline 9 & Argentina & 0 & 22 & 22 & 0.00 & 15.60 & 12.22 \\
\hline \multirow[t]{2}{*}{10} & Japan & 2 & 17 & 19 & 5.13 & 12.06 & 10.56 \\
\hline & Total India's ICP output & 39 & 141 & 180 & & & \\
\hline
\end{tabular}


papers each and 1 organization 222 papers. The productivity of top 25 most productive organizations varied from 11 to 222 publications per organization; together they contributed $60.75 \%$ (811) Indian publications share and $89.95 \%$ (8488) Indian citations share during 2000-09. Table 6 lists top 10 most productive and top 10 most impactful organizations.

Six organizations registered their publications output above their group average (32.44): AIIMS - New Delhi (222 papers), Amrita Institute of Medical Sciences, Coimbatore (73 papers), PGIMER - Chandigarh (64 papers), SCTIMST- Trivandrum (52 papers), Sri Jayadeva Institute of Cardiovascular Sciences and Research (SJICSR), Bangalore (48 papers) and Fortis Escort Heart Institute and Research Centre (FEHIEC), Delhi (42 papers) (Table 6).

Four organizations registered their citations per paper and relative citation index above the group average (10.47 and 1.48) of all organizations: Amrita Institute of Medical Sciences (AIMS), Coimbatore (33.88 and 4.79), SCTIMST - Trivandrum (30.73 and 4.35), Institute of Medical Sciences (IMS), BHU, Varanasi (17.20 and 2.43) and G.B. Pant Hospital, Delhi (11.33 and 1.60) (Table 6).

\section{Institutional Collaboration among Top 15 Most Productive Organizations}

Amongst top 15 most productive organizations, PGIMER-Chandigarh leads in collaboration linkages (38), followed by AIIMS - New Delhi (33 linkges), AIMS - Coimbatore and SCTIMST-Trivandrum (23 linkages each), etc. The collaboration between KEMH - Pune and SGSMC - Mumbai was the strongest with 10 linkages, followed by PGIMERChandigarh and SPGIMER-Lucknow (6 linkages), AIMS - Coimbatore and SCTIMST - Trivandrum (6 linkages), etc. (Table 7).

Table 4: Subject-Wise Breakup of Indian Publications in "Contenital Heart Defects" during 2000-19.

\begin{tabular}{|c|c|c|c|c|c|c|c|c|c|}
\hline \multirow[t]{2}{*}{ S.No } & \multirow[t]{2}{*}{ Subject* } & \multicolumn{3}{|c|}{ Number of Papers (TP) } & \multicolumn{2}{|c|}{ Activity Index } & \multirow[t]{2}{*}{$\mathrm{TC}$} & \multirow{2}{*}{$\begin{array}{c}\text { CPP } \\
2000-19\end{array}$} & \multirow[t]{2}{*}{ \%TP } \\
\hline & & 2000-09 & 2010-19 & $2000-19$ & 2000-09 & 2010-19 & & & \\
\hline 1 & Medicine & 375 & 865 & 1240 & 105.14 & 97.93 & 11271 & 9.09 & 92.88 \\
\hline 2 & $\begin{array}{c}\text { Biochemistry, Genetics and } \\
\text { Molecular Biology }\end{array}$ & 8 & 96 & 104 & 26.74 & 129.58 & 924 & 8.88 & 7.79 \\
\hline \multirow[t]{2}{*}{3} & $\begin{array}{c}\text { Pharmacology, Toxicology } \\
\text { and Pharmaceutics }\end{array}$ & 4 & 29 & 33 & 42.14 & 123.36 & 249 & 7.55 & 2.47 \\
\hline & & 384 & 951 & 1335 & 100.00 & 100.00 & & & \\
\hline - & There is overlapping of literat & overed u & various & jects & & & & & \\
\hline
\end{tabular}

Table 5: Distribution of India's papers on CHD by type of Heart Defects during 2000-19.

\begin{tabular}{|c|c|c|c|c|c|c|c|c|c|}
\hline \multirow[t]{2}{*}{ S.No } & \multirow[t]{2}{*}{ Type of Heart Defects } & \multicolumn{3}{|c|}{ Number of Papers } & \multicolumn{3}{|c|}{ Share of Papers } & \multirow{2}{*}{\multicolumn{2}{|c|}{$\begin{array}{l}\text { TC CPP } \\
2000-19\end{array}$}} \\
\hline & & 2000-09 & 2010-19 & 2000-19 & 2000-09 & 2010-19 & 2000-19 & & \\
\hline 1 & Hydroplasia & & & & & & & & \\
\hline 1.1 & Hypoplastic Left Heart Syndrome & 12 & 39 & 51 & 3.13 & 4.10 & 3.82 & 291 & 5.71 \\
\hline 1.2 & Hypoplastic Left Heart Syndrome & 5 & 16 & 21 & 1.30 & 1.68 & 1.57 & 126 & 6.00 \\
\hline 2. & Venticular Outflow Track Obstruction & & & & & & & & \\
\hline 2.1 & Pulmonic Stenosis & 1 & 3 & 4 & 0.26 & 0.32 & 0.30 & 61 & 15.25 \\
\hline 2.2 & Aortic Stenosis & 102 & 304 & 406 & 26.56 & 31.97 & 30.41 & 1429 & 3.52 \\
\hline 2.3 & Coarctation of the Aorta & 0 & 2 & 2 & 0.00 & 0.21 & 0.15 & 14 & 7.00 \\
\hline 2.4 & Bicuspid Aortic Valve Stenosis & 4 & 40 & 44 & 1.04 & 4.21 & 3.30 & 113 & 2.57 \\
\hline 2.5 & Subaortic Stenosis & 3 & 11 & 14 & 0.78 & 1.16 & 1.05 & 33 & 2.36 \\
\hline 3. & Septal Defects & & & & & & & & \\
\hline 3.1 & Ventricular Septal Defects & 83 & 267 & 350 & 21.61 & 28.08 & 26.22 & 1554 & 4.44 \\
\hline 3.2 & Atrial Septal Defects & 114 & 262 & 376 & 29.69 & 27.55 & 28.16 & 1425 & 3.79 \\
\hline 3.3 & Probe Patent Foramen Ovale & 0 & 1 & 1 & 0.00 & 0.11 & 0.07 & 7 & 7.00 \\
\hline 4.0 & Cyanotic Defects & & & & & & & & \\
\hline 4.1 & Truncus Arteriosis & 5 & 29 & 34 & 1.30 & 3.05 & 2.55 & 51 & 1.50 \\
\hline 4.2 & $\begin{array}{l}\text { Total Anamalous Pulmonary Venous } \\
\text { Connection }\end{array}$ & 7 & 26 & 33 & 1.82 & 2.73 & 2.47 & 44 & 1.33 \\
\hline 4.3 & Tetralogy of Fallout & 134 & 324 & 458 & 34.90 & 34.07 & 34.31 & 2010 & 4.39 \\
\hline 4.4 & Transposition of the Great Vessels & 49 & 155 & 204 & 12.76 & 16.30 & 15.28 & 788 & 3.86 \\
\hline \multirow[t]{2}{*}{4.5} & Tricuspid Atresia & 23 & 63 & 86 & 5.99 & 6.62 & 6.44 & 378 & 4.40 \\
\hline & & 384 & 951 & 1335 & & & & & \\
\hline
\end{tabular}


Table 6: Top 10 Most Productive and Top 10 Most Impactful Organizations in CHD in India during 2000-19.

\begin{tabular}{|c|c|c|c|c|c|c|c|c|}
\hline S.No & Name of the Organization & TP & TC & CPP & $\mathrm{HI}$ & ICP & $\% \mathrm{ICP}$ & $\mathrm{RCl}$ \\
\hline 1 & $\begin{array}{l}\text { Amrita Institute of Medical Sciences (AIMS), } \\
\text { Coimbatore }\end{array}$ & 73 & 2473 & 33.88 & 17 & 23 & 31.51 & 4.79 \\
\hline 2 & $\begin{array}{l}\text { Sree Chitra Tirunal Institute for Medical Sciences and } \\
\text { Technology (SCTIMST), Trivandrum }\end{array}$ & 52 & 1598 & 30.73 & 11 & 9 & 17.31 & 4.35 \\
\hline 3 & Institute of Medical Sciences (IMS), BHU, Varanasi & 15 & 258 & 17.2 & 5 & 2 & 13.33 & 2.43 \\
\hline 4 & G.B.Pant Hospital, Delhi & 18 & 204 & 11.33 & 6 & 1 & 5.56 & 1.6 \\
\hline 5 & $\begin{array}{l}\text { Sanjay Gandhi Postgraduate Institute of Medical } \\
\text { Sciences (SGPIMS), Lucknow }\end{array}$ & 22 & 207 & 9.41 & 7 & 0 & 0 & 1.33 \\
\hline 6 & $\begin{array}{l}\text { King Edward Memorial Hospital (Kem Hospital), } \\
\text { Pune }\end{array}$ & 23 & 214 & 9.3 & 8 & 1 & 4.35 & 1.32 \\
\hline 7 & $\begin{array}{l}\text { Seth Gordhandas Sunderdas Medical College } \\
\text { (SGSMC), Mumbai }\end{array}$ & 20 & 182 & 9.1 & 9 & 3 & 15 & 1.29 \\
\hline 8 & University of Mysore & 14 & 111 & 7.93 & 6 & 2 & 14.29 & 1.12 \\
\hline 9 & $\begin{array}{l}\text { All India Institute of Medical Sciences (AIIMS), New } \\
\text { Delhi }\end{array}$ & 222 & 1754 & 7.90 & 22 & 22 & 9.91 & 1.12 \\
\hline 10 & Christian Medical College (CMC), Vellore & 15 & 116 & 7.73 & 5 & 3 & 20 & 1.09 \\
\hline 11 & $\begin{array}{l}\text { Fortis Escort Heart Institute and Research Centre } \\
\text { (FEHIEC), Delhi }\end{array}$ & 42 & 244 & 5.81 & 7 & 5 & 11.9 & 0.82 \\
\hline 12 & Institute of Cariovascular Diseases (ICD), Chennai & 19 & 102 & 5.37 & 6 & 1 & 5.26 & 0.76 \\
\hline 13 & $\begin{array}{l}\text { Postgraduate Institute of Medical Education and } \\
\text { Research (PGIMER), Chandigarh }\end{array}$ & 64 & 267 & 4.17 & 10 & 2 & 3.13 & 0.59 \\
\hline 14 & $\begin{array}{l}\text { Sri Jayadeva Institute of Cardiovascular Sciences and } \\
\text { Research (SJICSR), Bangalore }\end{array}$ & 48 & 150 & 3.13 & 5 & 3 & 6.25 & 0.44 \\
\hline
\end{tabular}

TP=Total Papers; TC=Total Citations; $\mathrm{CPP}=$ Citations Per Paper; ICP=International Collaborative Papers; RCI=Relative Citation Index

Table 7: Institutional Collaboration among Top 15 Productive Indian Organizations in CHD during 2000-19.

\begin{tabular}{cccc} 
S.No & Name of the Organization & Number of Collaborative Linkages & Total Collaborative Linkages \\
\hline 1 & AIIMS - New Delhi & $2(5), 3(6), 4(6), 5(3), 6(3), 7(3), 11(1), 12(3), 15(3)$ & $33(9)$ \\
2 & AIMS - Coimbatore & $1(5), 3(2), 4(6), 5(3), 6(3), 14(1), 15(3)$ & $23(7)$ \\
3 & PGIMER - Chandigarh & $1(6), 4(4), 5(2), 6(2), 7(6), 12(3), 15(2)$ & $38(7)$ \\
4 & SCTIMST - Trivandrum & $1(6), 2(6), 3(4), 5(2), 6(2), 13(1), 15(2)$ & $23(7)$ \\
5 & SJICSR - Bangalore & $1(3), 2(3), 3(2), 4(2), 6(2), 7(1), 15(2)$ & $15(7)$ \\
6 & FEHIEC - Delhi & $1(3), 2(3), 3(2), 4(2), 5(2), 7(1), 13(2), 15(2)$ & $17(8)$ \\
7 & SGPIMS - Lucknow & $1(3), 3(6), 12(3)$ & $19(3)$ \\
8 & KEMH - Pune & $1(3), 5(1), 9(15)$ & $17(3)$ \\
9 & SGSMC - Mumbai & $1(1), 5(1), 8(15)$ & $2(2)$ \\
10 & ICD - Chennai & $1(1), 13(1)$ & $6(2)$ \\
11 & JIPMER - Pondicherry & $1(3), 3(3)$ & $4(3)$ \\
12 & CMC - Vellore & $4(1), 6(2), 11(1)$ & $1(1)$ \\
13 & G.B.Pant Hospital, Delhi & $2(1)$ & $11(5)$
\end{tabular}

\section{India's Top 25 Most Productive Authors}

397 authors participated in Indian research on CHD during 2000-19, of which 397 authors published 1-5 paper each, 65 authors 6-10 papers each, 35 authors 11-20 papers each, 6 authors 21-50 papers each and 5 authors 51-63 papers each and 1 author 58 papers. The research productivity of top 25 most productive authors varied from 11 to 63 publications per author. Together they contributed 50.04\% (668) Indian publications share and $48.27 \%$ (4555) Indian citations share during 200918. Table 8 gives detailed scientometric profile of top 10 most productive and top 10 most impactful authors.

- Seven of top 25 authors registered their publications output above the group average of 26.72: B. Airan and A. Saxena (63 papers each), 
S. Talwar (59 papers), S.S. Kothari (56 papers), S.K. Choudhury (51 papers), R.K. Kumar (43 papers) and R. Juneja (35 papers);

- Twelve of top 25 authors registered their citation per paper and relative citation index above the group average (6.83 and 0.96) of all authors: P. Khairy (16.31 and 2.31), B. Vaidyanathan (14.3 and
2.03), R.K. Kumar (10.53 and 1.49), U. Kiran (9.65 and 1.37), A. Saxena (9.54 and 1.35), S. Shrivastava (8.55 and 1.21), S. Chauhan (8.33 and 1.18), A. Bhan (8.24 and 1.16), R. Juneja (7.60 and 1.07), N.B. Ramachandra (7.55 and 1.07), S.S. Kothari (7.20 and 1.02) and R. Sharma (7.19 and 1.02).

Table 8: Top 10 Most Productive and Top 10 Most Impactful Indian Authors in CHD during 2000-19.

$\begin{array}{cccccccccc}\text { S.No } & \text { Name of the Author } & \text { Affiliation of the Author } & \text { TP } & \text { TC } & \text { CPP } & \text { HI } & \text { ICP } & \text { \%ICP } & \text { RCI } \\ 1 & \text { P. Khairy } & \text { Fortis Escort Heart Institute and } & 13 & 212 & 16.31 & 6 & 0 & 0 & 2.31 \\ & \text { Research Centre (FEHIEC), Delhi } & & & & & & \\ 2 & \text { B.Vaidyanathan } & \text { AIMS - Coimbatore } & 13 & 187 & 14.38 & 8 & 3 & 23.08 & 2.03 \\ 3 & \text { R.K. Kumar } & \text { AIMS-Coimbatore } & 43 & 453 & 10.53 & 12 & 15 & 34.88 & 1.49 \\ 4 & \text { U. Kiran } & \text { AIIMS - New Delhi } & 23 & 222 & 9.65 & 8 & 0 & 0 & 1.36 \\ 5 & \text { A. Saxena } & \text { AIIMS-New Delhi } & 63 & 601 & 9.54 & 13 & 7 & 11.11 & 1.35 \\ 6 & \text { S. Shrivastava } & \text { Fortis Escort Heart Institute and } & 11 & 94 & 8.55 & 3 & 0 & 0 & 1.21 \\ & \text { S. Chauhan } & \text { Research Centre (FEHIEC), Delhi } & & & & & & \\ 7 & \text { A. Bhan } & \text { AIIMS - New Delhi } & 21 & 175 & 8.33 & 7 & 1 & 4.76 & 1.18 \\ 8 & \text { R. Juneja } & \text { AIIMS - New Delhi } & 17 & 140 & 8.24 & 7 & 1 & 5.88 & 1.17 \\ 9 & \text { N.B. Ramachandra } & \text { AIIMS - New Delhi } & 35 & 266 & 7.6 & 11 & 2 & 5.71 & 1.07 \\ 10 & \text { S.S. Kothari } & \text { University of Mysore } & 11 & 83 & 7.55 & 6 & 0 & 0 & 1.07 \\ 11 & \text { R. Sharma } & \text { AIIMS - New Delhi } & 56 & 403 & 7.2 & 10 & 4 & 7.14 & 1.02 \\ 12 & \text { S.K. Choudhury } & \text { AIIMS - New Delhi } & 26 & 187 & 7.19 & 8 & 2 & 7.69 & 1.02 \\ 13 & \text { S. Talwar } & \text { AIIMS - New Delhi } & 51 & 278 & 5.45 & 8 & 2 & 3.92 & 0.77 \\ 14 & \text { B. Airan } & \text { AIIMS - New Delhi } & 59 & 258 & 4.37 & 8 & 4 & 6.78 & 0.62 \\ 15 & \text { AIIMS-New Delhi } & 63 & 269 & 4.27 & 8 & 4 & 6.35 & 0.60\end{array}$

TP=Total Papers; TC=Total Citations; CPP=Citations Per Paper; ICP=International Collaborative Papers; RCI=Relative Citation Index

Table 9: Collaboration among Top 15 Productive Indian Authors in CHD during 2000-19.

\begin{tabular}{|c|c|c|c|c|}
\hline 1 & B. Airan & AIIMS-New Delhi & $\begin{array}{l}\text { 2(27),3(42), 4(30), 5(42), 7(17), 8(9), 9(1), 10(3), 11(14), } \\
12(11), 14(9), 15(5)\end{array}$ & $210(12)$ \\
\hline 2 & A. Saxena & AIIMS-New Delhi & $\begin{array}{l}\text { 1(27), 3(18), 4(31), 5(21), 6(2). 7(28), 8(13), 9(1), 10(2), } \\
\text { 11(16), 12(9), 14(12), 15(7), }\end{array}$ & $185(13)$ \\
\hline 3 & S. Talwar & AIIMS - New Delhi & $\begin{array}{l}\text { 1(42), 2(18), 4(18), 5(41), 7(12), 8(5), 9(3), 10(5), 11(4), 12(2), } \\
14(2), 15(8)\end{array}$ & $160(12)$ \\
\hline 4 & S.S. Kothari & AIIMS - New Delhi & $\begin{array}{l}\text { 1(30), 2(31), 3(18), 4(20), 6(1), 7(21), 8(12), 9(1), 10(2), } \\
11(16), 12(13), 14(13), 15(7)\end{array}$ & $185(13)$ \\
\hline 5 & S.K. Choudhury & AIIMS - New Delhi & $\begin{array}{l}\text { 1(42), 2(21), 3(41), 4(20), 7(14), 8(8), 9(4), 10(2), 11(11), } \\
12(1), 14(8), 15(5)\end{array}$ & $177(12)$ \\
\hline 6 & R.K. Kumar & AIMS-Coimbatore & $2(2), 3(2), 4(1)$ & $5(3)$ \\
\hline 7 & R. Juneja & AIIMS - New Delhi & $\begin{array}{l}\text { 1(17), 2(28), 3(12), 4(21), 5(14), 8(7), 9(2), 10(2), 11(7), 12(2), } \\
\text { 14(8), 15(6), }\end{array}$ & $126(12)$ \\
\hline 8 & R. Sharma & AIIMS - New Delhi & $\begin{array}{l}\text { 1(9), 2(13), 3(5), 4(12), 5(8), 7(7),9(1), 11(12), 12(5), 14(15), } \\
\text { 15(1) }\end{array}$ & $88(10)$ \\
\hline 9 & U. Kiran & AIIMS - New Delhi & $1(1), 2(1), 3(3), 4(1), 5(4), 7(2), 8(1), 10(7), 11(1), 12(1), 14(1)$ & 23(11) \\
\hline 10 & S. Chauhan & AIIMS - New Delhi & $1(2), 2(2), 3(5), 4(2), 5(2), 7(2), 9(7), 11(1), 12(2), 15(1)$ & $26(10)$ \\
\hline 11 & P. Venugopal & AIIMS - New Delhi & $1(14), 2(16), 3(4), 4(16), 5(11), 7(7), 8(12), 9(1), 11(1), 12(10)$ & $93(10)$ \\
\hline 12 & U.K. Chowdhury & AIIMS - New Dellhi & $\begin{array}{l}\text { 1(11), 2(9), 3(2), 4(13), 5(1), 7(2), 8(5), 9(1), 10(2), 11(10), } \\
\text { 14(12) }\end{array}$ & $59(11)$ \\
\hline 13 & K.M. Cherian & $\begin{array}{l}\text { International Institute of Cardio } \\
\text { Thoracic and Vascular Disease }\end{array}$ & & \\
\hline 14 & A. Bhan & AIIMS - New Delhi & 1(9), 2(12), 3(2), 4(13), 5(8), 7(8), 8(15), 9(1), 12(12) & $80(9)$ \\
\hline 15 & S.K. Gupta & AIIMS - New Delhi & $1(5), 2(7), 3(8), 4(7), 5(5), 7(6), 8(1), 10(1)$ & $40(8)$ \\
\hline
\end{tabular}


Table 10: Top 10 Most Productive and Top 10 Most Impactful Journals in CHD during 2000-19.

\begin{tabular}{|c|c|c|c|c|c|c|}
\hline \multirow{3}{*}{$\begin{array}{l}\text { S.No } \\
1 \\
1\end{array}$} & \multirow{3}{*}{$\begin{array}{l}\text { Name of the Journal } \\
\text { International Journal of Cardiology }\end{array}$} & \multicolumn{3}{|c|}{ Number of Papers } & \multirow{2}{*}{\multicolumn{2}{|c|}{ TC $\begin{array}{c}\text { CPP } \\
2000-19\end{array}$}} \\
\hline & & \multirow{2}{*}{$\begin{array}{c}2000-09 \\
6\end{array}$} & \multirow{2}{*}{$\begin{array}{c}\text { 2010-19 } \\
7\end{array}$} & \multirow{2}{*}{$\begin{array}{c}2000-19 \\
13\end{array}$} & & \\
\hline & & & & & 242 & 18.62 \\
\hline 2 & Catheterization and Cardiovascular Interventions & 10 & 12 & 22 & 366 & 16.64 \\
\hline 3 & Journal of Cardiothoracic and Vascular Anesthesia & 13 & 13 & 26 & 303 & 11.65 \\
\hline 4 & Pediatric Cardiology & 14 & 11 & 25 & 244 & 9.76 \\
\hline 5 & Indian Journal of Pediatrics & 29 & 23 & 52 & 386 & 7.42 \\
\hline 6 & Heart Lung and Circulation & 7 & 4 & 11 & 69 & 6.27 \\
\hline 7 & Indian Pediatrics & 18 & 27 & 45 & 265 & 5.89 \\
\hline 8 & Congenital Heart Disease & 5 & 12 & 17 & 100 & 5.88 \\
\hline 9 & Annals of Thoracic Surgery & 9 & 12 & 21 & 121 & 5.76 \\
\hline 10 & Cardiology in the Young & 10 & 28 & 38 & 185 & 4.87 \\
\hline 11 & Indian Heart Journal & 68 & 42 & 110 & 503 & 4.57 \\
\hline 12 & Annals of Pediatric Cardiology & 4 & 80 & 84 & 344 & 4.1 \\
\hline 13 & Annals of Cardiac Anaesian & 6 & 47 & 53 & 184 & 3.47 \\
\hline 14 & Asian Cardiovascular and Thoracic Annals & 12 & 22 & 34 & 103 & 3.03 \\
\hline 15 & BMJ Case Reports & 0 & 26 & 26 & 17 & 0.65 \\
\hline
\end{tabular}

\section{Collaboration among top 15 authors}

Amongst top 15 most productive authors, B. Airan (AIIMS) leads in collaboration linkages (210), followed by A. Saxena and S.S. Kothari (AIIMS) (185 linkges each), S.K.Choudhury (AIIMS) (177 linkages each), etc. The collaboration between A. Airan and S. Talwar and B. Airan and S.K. Choudhury was the strongest with 42 linkages each, followed by S. Talwar and S.K. Choudhury (AIIMS) (41 linkages), A. Saxena and S.S. Chudhury (AIIMS) (31 linkages), etc. (Table 9).

\section{Medium of Research Communication}

Nearly $99.03 \%$ (1322) of CHD research in India appeared in 209 journals, $0.60 \%$ (8) in conference proceedings, $0.22 \%$ (3) in book series and $0.15 \%$ (2) as books. Of the 209 journals (reporting 1325 articles), 184 published 1-5 papers each, 13 published 6-10 papers each, 9 published 11-20 papers each, 11 published 21-50 papers each, 2 published 51-100 papers each and 1 published 110 papers each during 2000-19. The top 25 most productive journals accounted for $55.60 \%$ of total Indian output in journals during 2000-19, The 10-year output in journals decreased from $62.66 \%$ to $52.72 \%$ between $2000-09$ and 2010-19. Indian Heart Journal was the topmost productive journal (with 110 papers) in reporting Indian research in the field of CHD research, followed by Annals of Pediatric Cardiology (84 papers), Annals of Cardiac Anaesian (53 papers), Indian Journal of Pediatrics (52 papers) and Indian Pediatrics (45 papers) during 2000-19. In terms of citation per paper, International Journal of Cardiology leads in ranking (18.62), followed by Catheterization and Cardiovascular Interventions (16.64), Journal of Cardiothoracic and Vascular Anesthesia (11.65), Pediatric Cardiology (9.76) and Indian Journal of Pediatrics (7.42) (Table 10)

\section{CONCLUSION}

This paper analyzes India research in the domain of "Congenital Heart Defects" (CHD) based on few bibliometric indicators covering 20-year (2000-19) published research. During the 20 year period, CHD research by India registered a $10.0 \%$ average annual growth, contributed $3.04 \%$ share to global output, averaged citation impact of 7.07 citations per paper and only 55 papers are funded by funding agencies. About 180
(13.45\%) India's publications on CHD were involved in international collaboration during 2000-19, which increased from from $10.16 \%$ (39) during 2000-09 to $14.83 \%$ (141) during 2010-19. In all, 162 countries contributed to global CHD research (43888 publications). The top 10 most productive countries in the world alone accounted for $83.23 \%$ bulk share to global publications output in the subject. USA is in the leadership position in the world ranking (with $35.781 \%$ share). India ranks $10^{\text {th }}$ most productive country in the world with $3.04 \%$ share. The global publication share of other 8 amongst top 10 counties has been in single digit ranging between $3.75 \%$ and $8.43 \%$. The share of global publication increased in China, USA, India, Canada and Netherlands (from $0.48 \%$ to $5.52 \%$ ), as against decrease in Italy, France, Japan, U.K. and Germany (from $0.13 \%$ to $1.95 \%$ ) during 2000-09 to 2010-19

Medicine has been the preferred subjects in CHD research (with $92.88 \%$ publications share). Amongst the type of CHD research, "Tetralogy of Fallout" (458 papers, $34.31 \%$ ) contributed the largest publication output and share, followed by Aortic Stenosis (406 papers, 30.41\%)), Atrial Septal Defects (376 papers), Ventricular Septal Defects (350 papers, 26.22\%), Transposition of the Great Vessels (204 papers, 15.28\%), Tricuspid Atresia (86 papers. $6.44 \%$ )), etc

The distribution of India research in CHD by participating organizations is skewed. The top 25 organizations (out of total 431) contributed contributed $60.75 \%$ (811) Indian publications share and $89.95 \%$ (8488) Indian citations share during 2000-09, respectively during the period. AIIMS - New Delhi (222 papers), Amrita Institute of Medical Sciences, Coimbatore (73 papers), PGIMER - Chandigarh (64 papers) and SCTIMST- Trivandrum (52 papers) have been the most productive research organizations in the country. The organizations leading in terms of citation per paper and relative citation index were: Amrita Institute of Medical Sciences (AIMS), Coimbatore (33.88 and 4.79), SCTIMST Trivandrum(30.73 and 4.35), Institute of Medical Sciences (IMS), BHU, Varanasi (17.20 and 2.43) and G.B.Pant Hospital, Delhi (11.33 and 1.60) The distribution of India research by participating authors is highly scattered. The top 25 authors (out of total 397) across India contributed $50.04 \%$ (668) Indian publications share and $48.27 \%$ (4555) Indian citations shar respectively during the period. B. Airan and A. Saxena (63 papers each), S. Talwar (59 papers) and S.S. Kothari (56 papers) 
have been the most productive authors. The authors leading in terms of citation per paper and relative citation index were: P.Khairy (16.31 and 2.31), B. Vaidyanathan (14.3 and 2.03), R.K. Kumar (10.53 and 1.49), U. Kiran (9.65 and 1.37) and A. Saxena (9.54 and 1.35).

Indian Heart Journal was the topmost productive journal (with 110 papers) in reporting Indian research in the field of CHD research, followed by Annals of Pediatric Cardiology (84 papers), Annals of Cardiac Anaesian (53 papers), Indian Journal of Pediatrics (52 papers) and Indian Pediatrics (45 papers) are the top five most popular journals in the subject. International Journal of Cardiology leads in ranking (18.62) in terms of citation per paper, followed by Catheterization and Cardiovascular Interventions (16.64), Journal of Cardiothoracic and Vascular Anesthesia (11.65), Pediatric Cardiology (9.76) and Indian Journal of Pediatrics (7.42)

Conclude that pediatric cardiac care in India is still in its infancy. We have no data on congenital heart disease (CHD) prevalence at birth or on proportional mortality from CHD. The resources are not only limited but also are at times improperly utilized. There are very few specialized pediatric cardiology training programs, those that are, are concentrated in certain regions of India and are often imparted through combined adult and pediatric programs. The existing number of trained personnel for pediatric cardiology and pediatric cardiac surgery is inadequate. Above all there is no national policy for pediatric heart care. Increasing awareness of the problem amongst the pediatricians through CMEs, seminars, symposia is likely to be most helpful in early diagnosis and timely referral of cases. Training programs exclusively dedicated to pediatric cardiology and pediatric cardiac surgery need to be established in centres with good standards of pediatric cardiac care. ${ }^{6}$

\section{REFERENCES}

1. Meshram RM, Gajimwar VS. Prevalence profile and pattern of congenital heart disease in Central India: A prospective, observational study. Nig J Cardiol. 2018;15(1):45-9. http://www.nigjcardiol.orgtext.asp?2018/15/1/45/231967

2. Congenital Heart Defects. 2020. https://medlineplus.gov/congenitalheartdefects.html\#summary

3. Suluba E, Shuwei L, Xia Q. et al. Congenital heart diseases: genetics, noninherited risk factors and signaling pathways. Egypt J Med Hum Genet. 2020;21(11):1-2. https://doi.org/10.1186/s43042-020-0050-1

4. Congenital heart defect. 2020. https://en.wikipedia.org/wiki/Congenital_heart_ defect Accessed on 23.9.2020)

5. Saxena A, Relan J, Agarwal R, Awasthy N, Azad S, Chakrabarty M, et al. Indian guidelines for indications and timing of intervention for common congenital heart diseases: Revised and updated consensus statement of the Working group on management of congenital heart diseases. Ann Pediatr Card. 2019;12(3):254-86.

6. Saxena A. Congenital Heart Disease in India: A Status Report. Indian Pediatr 2018;55(12):1075-82F

7. Farhat T, Abdul-Sater Z, Obeid M, Arabi M, Diab K, Masri S, et al. Research in congenital heart disease: A comparative bibliometric analysis between developing and developed countries. Review Pediatr Cardiol. 2013;34(2):375-82. doi: 10.1007/s00246-012-0466-6. Epub 2012 Aug 10.

8. Hsieh W, Chiu W, Lee Y, et al. Bibliometric analysis of Patent Ductus Arteriosus treatments. Scientometrics. 2004;60(2):105-215. https://doi.org/10.1023/ B:SCIE.0000027793.12866.58

9. Doren SV, Brida M, Gatzoulis MA, et al. Sex differences in publication volume and quality in congenital heart disease: Are women disadvantaged?. Open Heart. 2019;6(1):e000882. doi: 10.1136/openhrt-2018-000882 